\title{
The Practice of Integrating Adaptation and Disaster Risk Reduction in the South-West Pacific
}

\begin{abstract}
Disaster risk reduction (DRR) and emergency management efforts are integral to climate change adaptation (CCA). The integration of disaster risk reduction with adaptation is globally recognized as a rational use of resources benefiting both areas. There is a substantial literature on the topic, but little on the practice of implementing such integration on the ground. This paper presents some of these experiences at national and agency levels in the south-west Pacific and outlines possible future directions to support policy and practice. Based on the perspectives of disaster risk reduction practitioners from Australia, Vanuatu and the Solomon Islands, it explores institutional changes with country examples, and the range of constraints and enabling factors in integrating adaptation and disaster risk reduction and emergency management practices. The Australian aim of spreading responsibility for CCA \& DRR integration through mainstreaming across departments and agencies was seen as effective in increasing whole of government approaches. However, in both Vanuatu and the Solomon Islands the concentration of information, responsibility and actions through a single focal point was more effective in reducing overlap and providing a clearer picture of what was being implemented, by whom and where. The findings demonstrate a need to consider the experiences arising from practical implementation of the integration agenda and to document the lessons from this experience in a way that can inform policy and practice.
\end{abstract}

Keywords: Climate Change Adaptation, Disaster Risk Reduction, Institutions, Small Islands, Australia, Integration

\section{Introduction}

Emergency management and disaster risk reduction (DRR) efforts are integral to climate change adaptation (CCA). This is because climate change is manifest most obviously through changing extremes - and partly as a result the integration of disaster risk reduction with adaptation is now globally recognized as vital for sustainable development (IPCC-SREX 2012). Climate change is projected to lead to more frequent and more intense climate and weather extremes, and in association with increases in exposure, will result in greater damage to human and environmental systems (Birkmann, 2011; IPCC -SREX 2012).

Climate change adaptation and disaster risk reduction have been posed as parallel but somewhat opposing issues and communities of practice (Gero, Méheux \& Dominey-Howes, 2011; Schipper, 2009; Thomalla, Downing, Spanger-Siegfried, Han \& Rockstrom, 2006; UNDP, 2009; UNISDR \& UNDP, 2012), which are dedicated to similar ends (Ireland, 2010; Schipper, 2009). Differences are most pronounced in the ways key concepts and terms, such as resilience, vulnerability and adaptive capacity, are interpreted and used. This has led to distinct differences in the way research, policy, and practice are carried out (Ireland, 2010; 
Moench, 2009; Schipper, 2009; UNDP, 2009). The different approaches stem partly from the different underlying origins of the problems they address. DRR institutions and policies were designed for effective immediate responses but not for long-term strategic policy (Handmer and Dovers, 2013). In contrast, climate change adaptation emerged as a result of science and projections of potential impacts accruing from climate change (Handmer and Dovers, 2013).

In current academic and policy discourse this integration is seen as desirable because it "could provide benefits at all scales" through vulnerability reduction and an increased focus on a multi-hazard approach (IPCC, 2012, p. 9; Field et al., 2014). Linking DRR with CCA can result in practical benefits such as increased access to a broader range of expertise, utilising growing international funds for adaptation, and embedding a more forward thinking approach in DRR by considering longer timeframes. Most disaster risk management strategies, frameworks and institutional arrangements are relatively well-established and thus may guide the incorporation and management of climate change adaptation (McAdam, 2012; Rivera, 2014). Yet, little published material provides clear practice-based insights on how DRR/EM agencies and institutions are integrating this policy agenda into their activities (exceptions see eg Rivera, 2014).

This paper starts to fill this gap by presenting practitioners' experiences with the integration agenda in the south-west Pacific region. To examine the issue of integration in practice research project was organized with a co-production approach using a roundtable and series of discussions. In particular, the project set out to identify the key institutional challenges, and the strategies or governance arrangements to overcome them. The participants included disaster risk management and climate change representatives from Vanuatu, Solomon Islands, the Australian states of NSW, Victoria and Queensland, as well as the Australian National government, and the NGOs of Surf-Life Saving Australia and AFAC (Australasian Fire \& Emergency Services Authorities Council, representing all fire and emergency services organisations in Australia and many from the Pacific), Griffith University and RMIT University. The project also addressed the Australasian experience with, and capacity for, emergency management, and its potential to contribute to climate change adaptation across the region. Note that for the purposes of this paper, "emergency management" and "disaster risk reduction" (DRR) are treated as similar as throughout Australia and the South-west Pacific "emergency management" is used in government, although the international terminology of DRR is increasingly commonplace. For an explanation of the Australian emphasis on risk reduction in emergency management see EMA (2004).

The paper starts with the evolving institutional context in the Pacific and outlines the main themes that emerge from research carried out so far on the topic. The third section discusses the varied interpretations of how integration should take place within the institutional landscape and uses Vanuatu and the Solomon Islands as examples of institutional reform. The fourth and fifth sections examine specifically the types of constraints and enablers that were seen by the practitioners to sit at the core of integration. The final section discusses the country experiences with the broader integration agenda.

\section{Integrated Climate Change Adaptation and Disaster Risk Reduction in the South- West Pacific}

At the global level, disaster risk reduction is increasingly expected to consider climate change in its practices due to the influence of climate change on disaster risk (Table 1). To this end, 
the Hyogo Framework for Action (HFA) gives explicit recognition to climate adaptation's importance for disaster risk reduction (UNISDR Asia and Pacific secretariat, 2011; UNISDR, 2013a). The UNFCCC Bali Action Plan (2007) and the Cancun Adaptation Framework (2010) both call for more recognition of DRR as part of the climate adaptation agenda. The push for integration is evident in UNFCCC policy frameworks such as the Joint National Action Plans (JNAPs) for climate change and disaster risk management, as developed for example in the Pacific nations of Tonga (Kingdom of Tonga, 2010), Tuvalu, and Cook Islands. The Solomons Islands instead has pursued a strategy on resilient development, which embeds CCA \& DRR considerations into development planning (UNISDR, 2013b), whereas Vanuatu has developed an integrated national draft policy on Climate Change and Disaster Risk Reduction. A new Pacific wide integrated strategy is currently being drafted that will replace the Pacific Disaster Risk Reduction and Disaster Management Framework for Action 2005-2015 and the Pacific Islands Framework for Action on Climate Change 2006-2015 that have been guiding regional activities (SPC, UNISDR \& SPREP, 2013). This highlights that integration can be done in different ways: for example through mainstreaming CCA into existing DRR arrangements and frameworks (Rivera, 2014) or by developing new policies and frameworks that combine DRR and CCA such as Joint National Action Plans (JNAPs).

In addition to these policy frameworks, the literature on the idea and theory of integration is well advanced (Birkmann\& Teichman, 2010; Gero, Méheux \& Dominey-Howes 2010, 2011; IPCC, 2012; Ireland, 2010; Mercer, 2010; Schipper, 2009; Thomalla, Downing, SpangerSiegfried, Han \& Rockstrom, 2006; UNDP, 2009). A range of publications now highlight the generic factors that are most commonly found in integration contexts Gero et al., 2010, 2011; Thomalla et al., 2006; UNISDR \& UNDP, 2012; UNISDR Asia and Pacific Secretariat 2011). For example, it is common to assume that an integrative approach will minimize overlap and duplication of projects and programmes, results in more efficient approaches, reduces administrative burdens, and increases the potential to consider multiple goals simultaneously (Table 2). Similarly, a range of barriers and enablers for integration have been identified, which are used to explain why the integration agenda is not necessarily progressing and what could be done to ease the process. Some authors have however questioned whether the lines dividing the CCA and DRR communities are more theoretical than of practical value: for example, Mercer (2010) reports that at community level in Papua New Guinea, there is little difference from the community's perspective whether activities are classified as DRR or CCA.

As set out in Table 2, common constraints include the different and overlapping frameworks, funding channels and activities, which have for instance led to the development of separate work streams with limited collaboration between agencies and departments, lack of capacity and expertise to implement the work streams effectively, and lack of robust Monitoring and Evaluation tools to document the benefits arising from both CCA and DRR activities. A significant barrier is the DRR's consistent focus on current disasters where CCA might not be prioritised due to its focus on long-term strategic planning. For example, in the Pacific, many disaster management strategies continue to be highly reactive (Nunn, 2009). Enabling factors for integration in turn include better access to weather and climate information, greater synergies between sectors and agencies, improved access to finance, and combining the CCA and DRR activities with the broader development agenda. Finding relevant entry points is also crucial for the integration as both CCA and DRR are relevant to a wide range of issues such as food security and water management among others. 
The aim of this paper is to present some of these experiences of practitioners at national and agency levels in the south-west Pacific region and to outline possible future directions to support policy and practice. The paper draws on the findings of a small-scale research project that included a regional roundtable on emergency management for climate change adaptation in Australia and the South-west Pacific. It aimed to examine how the considerable Australian and regional experience with, and capacity for, emergency management can and should contribute to climate change adaptation. It also examined what implications climate change might have for the work of emergency management across the region. The aim was also to facilitate networks and partnerships between different actors and institutions in the South Pacific attending the roundtable discussions. The research results reflect the perceptions and personal experiences of the practitioners and policymakers who attended the roundtable and subsequent discussions. These views and experiences in some cases differ from the existing literature and official governance structures concerning the integration of EM/DRR and CCA in the region.

The methods included qualitative approaches such as informal discussions with a range of institutional representatives (Punch, 2005) and a roundtable discussion with predetermined themes. The roundtable discussions were written down word for word where possible and the thematic analysis of the notes included the identification of constraints to integration and facilitating factors, potential learning across jurisdictions, and possible improvement in approaches to disaster risk reduction and climate adaptation. The analysis process was based on a combination of existing literature and both the predefined and emergent themes from the roundtable discussions and related discussions. This approach neither completely relies on existing literature nor only relies on the data itself (Bernard and Ryan, 2010; Dey, 1993). The next section examines the institutional change processes for greater integration in Vanuatu and the Solomon Islands where after the range of constraints and potential enabling factors are discussed.

\section{Institutional processes for integration: Vanuatu and the Solomon Islands}

Interesting comparisons emerged between the varied experience between Australian states and agencies and that of Vanuatu and the Solomon Islands. An important theme was that of institutional change and preferences: with different approaches to integration, and different priorities for institutional reform. For the Pacific Island countries, integration across agencies and departments to provide one national focal point responsible for CCA \& DRR (increases effectiveness of coordination) was favoured, especially as it reduces the administrative burden and allows focus on national priorities. For Australian states, there was a preference for mainstreaming CCA \& DRR across agencies and sectors making the issues everyone's responsibility and increasing ownership across government) (Eburn \& Jackman, 2011).

However, the project participants identified problems with both the approaches. For example, a single focal point had the potential to lead to a siloed approach, where integration could be seen as the exclusive responsibility and mandate of one particular department or unit. This could discourage other departments from taking part and incorporating integrative approaches. Mainstreaming integration across the government could in turn lead to uncoordinated approaches, lack of a dedicated budget, and defy clear identification of responsibility. 


\subsection{Institutional change in Vanuatu and Solomon Islands}

Vanuatu:

The experiences in Vanuatu and the Solomon Islands illustrate different pathways towards greater institutional integration and integration in practice. In Vanuatu's case, to a large extent the integration agenda was driven by the NAB (National Advisory Board) co-chair agencies i.e. the Vanuatu Meteorology and Geo-hazards Department (VMGD) and the National Disaster Management Office (NDMO) director. The integration had mainly taken place through the consolidation of Climate Change Adaptation and Disaster Risk Reduction into a combined institutional arrangement (NACC \& NTF, 2012). This was mainly in the form of the Vanuatu National Advisory Board (NAB) for Climate Change and Disaster Risk Reduction. The Board considers project proposals and seeks to maintain coordination of the different initiatives across the country. Civil society members are also part of the NAB in order to facilitate multi-stakeholder discussions and agreement. A Project Management Unit (PMU) supports NAB in both project implementation and advice. Donor funding from several climate change projects has made the unit possible (EU's Global Climate Change Alliance Project (EU GCCA) and the World Bank’s Increasing Resilience to Climate Change and Natural Hazards Project (IRRCNH)).

The main challenges for the integration process lie in the coordination of activities across government sectors and departments (NAB, 2014), and in managing the expectations of funders in relation to PMU activities. Integration has also meant a re-orientation of traditional jurisdictions, which has resulted in lingering uncertainties around roles and responsibilities. This is particularly true of the roles of PMU and other departments within the VMGD and NDMO relative to both CCA and DRR. Additionally having a single focal or coordination point means forging a balance between the high demand from partners versus the limited and time constrained NAB Secretariat staff.

Leading up to the creation of the NAB, Vanuatu's integration process was characterised by: duplication or overlaps between previous bodies responsible for climate change and disaster management; lack of coordination among the various levels of governance (i.e. national to community level); increasing number of actors; resource availability; international and regional integration efforts; need for a coordination unit or resourced secretariat; and donor support. Prior to the NAB, the National Advisory Committee on Climate Change (NACCC) and National Task Force (NTF) were two inter-agency bodies that had separate responsibilities for matters related to either climate change adaptation or disaster risk reduction. Membership of both NACCC and NTF was similar, and with growing resources, actors, a lack of activity and program coordination, it made sense to consolidate these resources.

Given that the integration process is still in its infancy, much effort is needed to communicate and implement new coordination mechanisms to reach more people and stakeholders. Moreover, efforts to establish new communication mechanisms are inclusive of other "busy" work namely development of infrastructure such as terms of reference, procedures and guidelines. In effect, since the NAB Secretariat was established through project funding, balancing project management with strategic coordination functions has been challenging. Therefore there is the need to manage the expectations of both PMU and its partners.

Solomon Islands: 
In the Solomon Islands, the institutional integration was still underway but was being conducted and strengthened through a number of policies, strategies, frameworks and legislation. Discussions have taken place to develop a joint framework for resilient development, which would mainstream CCA and DRR into development planning and as part of the National Development Strategy (UNISDR, 2013b). The formation of a new ministry in 2008 placed climate change, environment/conservation and meteorology under the same ministry and enabled a more targeted use of resources to address these policy areas. Another factor supporting the integration was the rise in climate change issues globally, regionally and nationally, which resulted in the need for it to be a separate division. Previously climate change was in a small unit within the Meteorological service.

The main challenges for the integration have been a lack of communication and connections between donors and the national government when it has come to developing and enforcing climate change related frameworks. The experience in the Solomons points to the difficulty of having myriad frameworks, policies and regulations in place that are supposed to showcase the most prominent priorities and directions. For example, The Solomons has conducted its UN-supported National Adaptation Plan for Action (NAPA), National Adaptation Plan (NAP), and Joint National Action Plan (JNAP), which are all supposed to provide direction for climate change adaptation. On top of these plans, there are national policies, such as the Climate Change Policy 2012-2017, and other strategies, frameworks and legislation, including DRR (Disaster Risk Management Plan 2010) and CCA, and climate change communication. National frameworks for climate change adaptation, such as the NAPA, NAP, and JNAP, that have been developed for the Solomon Islands often by external funders do not necessarily link or align with national priorities, policies and legislation. This has been partly dealt with through enhanced communication between different parties and closer alignment of country priorities and needs with donor funding priorities.

In the Solomons, the experience has been that many external funders work outside the current governance structures, and often do not connect or align with country priorities and needs. The Solomons' approach therefore has been to focus more closely on resilient development and to reduce overlap and duplication between different agencies with the slogan "stop filling a vacuum, help us to fill the vacuum”. This has enabled more collaborative approaches where priorities and assessment methods are discussed between the parties where country priorities and donor interests can be aligned more effectively. However, underlying problems in the everyday operational environment of emergency response also hinder integration and activities.

Some examples of integration are the Solomon Islands Climate Change Assistance Program (provided by EU general budget support) and CRISP (World Bank implemented program), which show a clear integration of CCA \&DRR. Integration can also be achieved through negotiation: recently two large donor project proposals were seen to have significant overlap and duplication both in terms of activities and geographical focus. The Solomon government officials identified the overlaps, and negotiated with the donors to make the projects complementary rather than overlapping.

\section{Constraints to integration}


The literature reports that common constraints or barriers to integration include: capacity constraints (inefficient coordination, lack of communication, lack of political will, insufficient funds, lack of capacity and expertise); separation of major frameworks and organisations directing CCA \& DRR (global, regional, national) and separate funding streams; and different disciplinary and expert community involvement (Gero, Méheux \& Dominey-Howes, 2010, 2011; Handmer and Dovers, 2013; Rivera, 2014; Thomalla, Downing, Spanger-Siegfried, Han \& Rockstrom, 2006; UNISDR \& UNDP, 2012; UNISDR Asia \& Pacific Secretariat 2011). The practitioners in this research identified further issues that are explored in this section (Table 3).

\subsection{Uncertainty relating to the changing nature of events}

A primary concern is the changing nature of climate and weather events, and the implications for both CCA \& DRR. Some participants felt that these changes were noticeable in terms of sequencing of events. 'Events' in this context are a function of weather and climate, and the exposure and vulnerability of humans, their activities and assets. Uncertainty relates to how events will change in the future, how they will interact with growing exposure, and what this means for both CCA \& DRR activities and agency practice. This concern is well documented in the research literature (eg IPCC 2012).

In Australia and the South Pacific, the increased frequency of extreme weather and climate events is stretching the response capacity of agencies. The changing nature of events also impacts on the volunteer sector, which is heavily relied upon during crises. Some participants noted that many Australian emergency management volunteers were also professionals dealing with both CCA \& DRR. Therefore, the volunteer capacity and capability to continuously respond to crises and events would decrease if events began occurring more frequently and in greater magnitude. The concern was that there was no real understanding of the response capability and capacity within agencies or within the region to deal with more frequent disasters and extreme events.

In addition, a lack of dialogue between operational and policy communities was identified as a constraint, as policy priorities and operational realities do not always inform each other and can come into conflict. For example, in Australia, the policy and planning professionals do not always necessarily engage with those who work on frontline DRR activities while practitioners might not have ways to access the policy and planning process.

\subsection{Current institutional arrangements}

Aspects of DRR, in particular emergency response, overlap with police responsibilities (both in Australia and the South Pacific), and can complicate targeted capacity building within CCA \& DRR sectors. For example, in the Pacific training targeted at CCA \& DRR personnel is often attended by police but not by fire service staff because of overlap. In Vanuatu and Solomons, there have therefore been attempts to separate fire services institutionally from the police services (AFAC, 2013). As also mentioned above under "uncertainty", a challenge in Australia is the reliance on the volunteer sector during disasters, in that the limits of the capacity of the formal or official volunteer sector are unclear. The increasing professionalization of emergency management also means that it is seen increasingly as the 
responsibility of service providers rather than as a whole-of-society responsibility. Community expectations and reliance on government and service providers also makes it difficult to activate community members to undertake actions themselves. The participants also recognised land use planning as a key issue with obvious consequences for DRR and CCA, yet the institutional arrangements often did not give opportunity for DRR and CCA professionals to provide input.

\subsection{Complex external funding structures}

The participants noted that in the South-West Pacific there are many active funding (or donor) organisations, each with its own terminology, and own approach to project management, accountability and reporting, among other requirements. Most of these requirements are experienced as inflexible and resource and expertise intensive. This is a problem worldwide, with some countries facing the distinct requirements of hundreds of donors simultaneously, imposing a nearly impossible burden on the recipient government, leading to calls for donors to harmonise their requirements (Mawdsley, Savage \& Kim, 2014). The need to work with these different systems in the Pacific along with a continuing preference by funders for demonstration or pilot projects inhibits progress, increases funding uncertainty for programs and staff, and constrains effective collaboration and integration. The current experiences of practitioners pointed to the need for an implementation program for CCA and DRR rather than seemingly continuous pilot and investigative studies for new approaches. In Australia, funding structures (from federal to local) similarly pose difficulties in supporting local government priorities as most funding is decided on the national or state level and does not necessarily reflect local priorities.

\subsection{Limited Monitoring, Evaluation and learning mechanisms}

Both in Australia and in the South Pacific, lack of effective Monitoring \& Evaluation (M\&E) mechanisms inhibits effective learning and program improvement. It was not clear to the practitioners whether the approaches, methods, tools, and assessments that were being used to increase disaster resilience were instigating lasting change on the ground. Without appropriate or robust M\&E mechanisms, some of the practitioners felt it was difficult to demonstrate to communities, government agencies or other entities that projects and programs had actually resulted in increased community resilience. The lack of M\& E in many projects also meant that the lessons identified were often lost and not learned, as there were limited opportunities to collate the information on successes and failures, and it was often unclear how the collated "lessons" would be considered for incorporation into practice. Paradoxically, for the Pacific Island countries, donor M \& E requirements were often very demanding in terms of time and resources, but ineffective in terms of learning. The issues surrounding monitoring, evaluation and learning in DRR are well documented in the literature (eg US Wildfire Lessons Learned Center, 2011) and in government reports (eg. AGD, 2012).

\section{Strategies to enable integration}


The constraints identified above at times severely hampered both the practice and integration of CCA and DRR. However, the participants also identified a range of enabling factors, which had the potential to overcome some of the constraints. These enabling factors are presented below (Table 4) and here we discuss some of these in more detail.

\subsection{Increased response capacity}

Proactive planning in place before disasters occur can facilitate staff movement in the region, to promote sharing of knowledge and experience to increase capacity for response and for prevention. Response capacity at national, regional and agency levels needs to be enhanced through proactive planning through, for example, capacity and capability assessments to allow resources to target weaker areas. In Australia, work has started in the form of an Australian National Capability Picture, which lists and tracks the existing skills and expertise in the country and functions as a 'clearinghouse' for assessing national capabilities and skills. This should enable more rapid deployment of expert staff in times of disasters, knowing where such skills and professionals were located, and having a better understanding of what external assistance and experts would be needed.

In Australia, placing of disaster coordination liaison officers in each state is a proactive approach whereby networks are in place before an event occurs - these approaches could also apply at the regional level. Note that the points about capacity ignore the capacity potentially available through informal or unofficial volunteers - people who are not formally affiliated with an emergency management organisation. These groups have become prominent recently following the 2011 Brisbane floods (eg see Volunteering Queensland) and the Christchurch earthquakes (eg see University of Christchurch Student Volunteer Army).

A regulatory framework should be in place before disasters occur to facilitate rapid deployment of DRR personnel within the region. For example, during the Samoan tsunami in $29^{\text {th }}$ of September in 2009 and its aftermath, a clear policy framework would have been useful in deploying EM personnel from PNG and Fiji to Samoa. This would also help in identifying the right points of entry among institutions and disaster relief coordination. Such frameworks have the capacity to help coordinate activities in the region, and also with directing help effectively to where it is most needed. For example, some types of specialist expertise could be held at the regional rather than country level and deployed as required throughout the region. While broader scale arrangements exist, such as those from the UN Office for the Coordination of Humanitarian Activities (UNOCHA), the practitioners identified a need for a more responsive and region-specific network and framework.

\subsection{Strengthened formal and informal partnerships}

In the region, fostering formal (through policy frameworks) and informal partnerships (through personal relationships) is important for effective collaboration. These can take the form of alliances, networks, and joint proposals across agencies and sectors. Informal partnerships have included for example agency-to-agency exchanges between Fiji and Victoria where emergency management personnel have been able to spend time at the partner agencies. For example, staff from CFA (Country Fire Authority) Victoria had undertaken placements at the Fiji National Fire Authority to build capacity and to understand how to adapt EM plans and policies for local context, and vice versa. Such low-overhead twinningarrangements have strengthened the opportunities to learn from practice. 
Greater integration had brought new alliances into the area, such as the Pacific Islands Emergency Management Alliance, and made new space for collaborative approaches where different people and institutions could pursue joint projects. Partnerships could be managed through joint agency proposals where the data and resources gathered would be useful across a number of agencies. This would enable closer collaboration and sharing of information across government. Civil society actors, such as NGOs and church groups, should be viewed as an essential additional resource for governments to implement the climate change and disaster risk reduction agenda, and to gain support for policies and actions. Regional organisations, such as SPC and SOPAC, were also seen as significant in increasing the capacity and skills in the region.

\subsection{Leadership, Access to data and Science/Policy connections}

Political will and leadership are important for effective integration because of the need for institutional change. In Australia, there is a need to better incorporate science (in the sense of research based evidence) into decision-making. In the South Pacific, it is important to have access to data across agencies, and to provide a legislative basis for integration. Data issues related to the sharing of knowledge as well as to learning about new ways to use and analyse relevant data (Southgate et al., 2013). The notion of evidence-based practice and the utilisation of relevant data in policy and decision-making processes were also noted as key factors that could enable more robust practice. Legislation was seen as an important driving force, for example in enhancing resilience and enabling better planning through building codes, which provide a legislative mandate for accountability and responsibility, and can thereby be used to drive integration. The concepts of accountability and responsibility in integration are central as these allow parties to commit to actions and function as an added incentive to implement integration (UNISDR \& UNDP, 2012).

\section{Discussion and Conclusions}

The different institutional pathways for integration provide an interesting comparison as to the rationale behind institutional change and reform in implementing integration. The Australian approach of spreading responsibility for integration through mainstreaming across departments and agencies was seen as effective in increasing whole of government approaches. Instead, both Vanuatu and Solomon Islands demonstrate a different approach where the concentration of information, responsibility and actions through a single focal point was seen as more effective in reducing overlap and providing a clearer picture of what was being implemented, by whom and where. The preference for such a focal-point approach may partly be attributed to the role of regional frameworks. These include the Pacific

Disaster Risk Reduction and Disaster Management Framework for Action 2005-2015 and the Pacific Islands Framework for Action on Climate Change 2006-2015 that have been guiding regional activities, and are now in the process of integration towards a joint comprehensive strategy for sustainable development (SPC, UNISDR \& SPREP, 2013) and associated donor requirements and preferences for institutional reform. In the context of often extremely limited government capacity, integration and a single focal point seems a logical, albeit not the only, step in enhancing the capacity and delivery of improved DRR.

The experiences discussed in this paper show that many of the underlying issues relevant for DRR and emergency management can also support a more robust climate adaptation agenda. For example, modifying current approaches, frameworks and networks among institutions and agencies as well as the accessibility and use of data for decision-making are desirable for 
improved practice. Harmonising and using the existing systems and standards in the recipient countries could provide more feasible entry points for CCA \& DRR and increase implementation rather than continuing with multiple donor reporting requirements, frameworks and guidelines specific to each agency and policy issue. Practitioners are clearly aware of the current constraints and capacity needs in their respective agencies and institutions, and have identified a range of current processes, such as partnerships and agency-to-agency placements, which are building and co-producing enhanced capacity for DRR in the region. One of the cross-cutting concerns is the lack of monitoring and evaluation mechanisms for governments, regional agencies, communities and NGOs to better understand the process and practice of CCA and DRR integration, and factors related to community resilience and its practical assessment. Here, strengthening the linkages between science and policy will also provide opportunities for more robust approaches (Southgate et al., 2013).

While DRR is often perceived as reactive event-based practice, the move towards more proactive thinking was evident in many of the examples to enable agencies to respond faster and better to multiple risks under changing demographics and climate. For example, participants recognised the need to set up regional frameworks and policies that could enable rapid coordination of personnel and resources in times of extreme events. One key issue was the assessment of response capacity and capability at agency, country and regional levels. Gaining a better understanding of the current status of capacity and capability to respond to multiple simultaneous extreme events was deemed a core component in constructing more robust and efficient practice. This should go beyond individual countries to a regional assessment that includes civil society.

Some similarities were identified between Australian states, Vanuatu, and the Solomon Islands including geographical isolation of communities and challenges in securing safe evacuation mechanisms during disasters. For Pacific island countries, part of the challenge also lies in the core-periphery divide where most investments take place in the more developed 'core' areas (Nunn, 2009). Peripheral communities in particular hold many different kinds of knowledge that are relevant for both DRR and CCA, which should be also appreciated and considered (Walshe and Nunn, 2012). Sharing knowledge and experiences across the region was deemed crucial as this has the potential to harness the lessons learned from different contexts. At the regional level, organisations, such as AFAC and Surf Life Saving Australia, have fostered both formal and informal networks and supported capacity building activities that are relevant in responding to the dual challenges of CCA \& DRR. These networks and personal relationships are effective ways to foster closer collaboration and cooperation in the region, which is also acknowledged by other research (see Gero et al., 2014).

However, it would appear that the problem often is not the practical implementation of CCA \& DRR integration but more systemic and contextual issues such as relationships, responsibilities and expectations between government agencies and other actors, such as international donors and non-governmental organisations. In addition, one needs to consider who is driving the frameworks and regulations for greater integration and to what extent these result in tangible increases in local capacity to undertake improved DRR. This demonstrates the need to build local response capacity but it also shows the importance of regional support as part of in-country disaster management efforts - whether as part of DRR, CCA or both. Given that the integration agenda is still fairly new, further policy and research work should focus on documenting the experiences of those responsible for on-the-ground implementation and institutional change. 


\section{References}

Attorney General's Department [AGD]. (2012). Summary Report of the National Security and Knowledge and Lessons Management Workshop, 13-17 November 2011 (Australian Government).

Bernard, H. R., \& Ryan, G. W. (2010). Analyzing qualitative data: systematic approaches. Thousand Oaks, Calif.: Corwin.

Birkmann, J. (2011). First- and second-order adaptation to natural hazards and extreme events in the context of climate change. Natural Hazards, 58, 811-840.

Birkmann, J. \& Von Teichman, K. (2010). Integrating disaster risk reduction and climate change adaptation: key challenges—scales, knowledge, and norms. Sustainability Science, 5, 171-184.

Dey, I. (1993). Qualitative data analysis: a user-friendly guide for social scientists. London: Ebooks Corporation, New York: Routledge.

Eburn, M. and Jackman, B. (2011). Mainstreaming fire and emergency management into law. Environmental and Planning Law Journal 28, 59-76.

EMA (Emergency Management Australia) (2004). Emergency Management in Australia concepts and principles. Emergency Management Handbook \# 1. Canberra: Attorneys General Department, Australian Government.

Gero, A., Méheux, K. \& Dominey-Howes, D. (2010). Disaster risk reduction and climate change adaptation in the Pacific: The challenge of integration. Australian Tsunami Research Centre - Natural Hazards Research Laboratory, University of New South Wales, Sydney.

Gero, A., Méheux, K. \& Dominey-Howes, D. (2011). Integrating disaster risk reduction and climate change adaptation in the Pacific. Climate and Development, 3, 310-327.

Gero, A., Fletcher, S. M., Rumsey, M., Thiessen, J., Kuruppu, N., Buchan, J., Daly J. \& J., W. (2014). Disasters and climate change in the Pacific: Adaptive capacity of humanitarian response organisations. Climate and Development.

Girot, P., Ehrhart, C. \& Oglethorpe, J. (2012). Integrating Community and Ecosystem-Based Approaches in Climate Change Adaptation Responses. Ecosystem and Livelihoods Adaptation Network (ELAN): http://www.careclimatechange.org/files/adaptation/ELAN_IntegratedApproach_150412.pdf, accessed 27.11.2012.

Handmer, J. W., \& Dovers, S. (2013). Handbook of Disaster Policies and Institutions: Improving Emergency Management and Climate Change Adaptation: Earthscan: London and Sterling, VA.

IPCC (2012). Summary for Policymakers. In: Managing the Risks of Extreme Events and Disasters to Advance Climate Change Adaptation In: Field, C. B., V. Barros, T.F. Stocker, D. Qin, D.J. Dokken, K.L. Ebi, M.D. Mastrandrea, K.J. Mach, G.-K. Plattner, S.K. Allen, M. Tignor, and P.M. Midgley (ed.) A Special Report of Working Groups I and II of the 
Intergovernmental Panel on Climate Change. Retrieved 7 March, 2012 from http://ipccwg2.gov/SREX/.

Ireland, P. (2010). Climate change adaptation and disaster risk reduction: Contested spaces and emerging opportunities in development theory and practice. Climate and Development, 2, 332-345.

Kingdom of Tonga (2010). Joint National Action Plan on Climate Change Adaptation and Disaster Risk Management 2010-2015 Second National Communication Project, Ministry of Environment and Climate Change (MECC) and National Emergency Management Office (NEMO), Tonga July 2010. Retrieved 12 October, 2012 from http://www.sprep.org/att/irc/ecopies/countries/tonga/66.pdf.

McAdam, J. (2012). Climate Change, Forced Migration, and International Law. Oxford Scholarship Online: May 2012.

Mawdsley, E., Savage, E., and Kim S. (2014). A 'post-aid world'? Paradigm shift in foreign aid and development cooperation at the 2011 Busan High Level Forum. The Geographical Journal 180(1), 27-38.

Mercer, J. (2010). Disaster risk reduction or climate change adaptation: Are we reinventing the wheel? Journal of International Development, 22, 247-264.

Moench, M. (2009). Adapting to climate change and the risks associated with natural hazards: methods for moving from concepts to action, pp. 249-280 In: Schipper, E. L. F. \& Burton, I. (eds.) The Earthscan reader on adaptation to climate change. London ; Sterling, VA: Earthscan.

NAB (2014). Risk governance assessment report draft: Strengthening climate and disaster risk governance in Vanuatu. National Advisory Board on Climate Change and Disaster Risk Reduction, Republic of Vanuatu, with assistance from Pacific Risk Resilience Project, UNDP.

NACC and NTF (2012). Report and Outcomes of the NACCC \& NTF Reorientation Workshop 6-7 February 2012. National Advisory Committee on Climate Change and National Task Force, Government of Vanuatu.

Norton, J. (2011). Issues for Integration of DRR and CCA in Solomon Islands. Climate Change Adaptation and Emergency Management, RMIT Centre for Risk and Community Safety Workshop on Research and Policy - Fri 20 May 2011, Session on Practitioners and policy makers - what we need. Retrieved 12 October, 2012 from http://media.emergencymanagement.org.au/uploads/john_norton_may_20_2011.pdf.

Nunn, P. (2009). Responding to the challenges of climate change in the Pacific Islands: management and technological imperatives. Climate Research, 40, 211-231.

AFAC (2013). Pacific Islands Fire Services Association, Partnerships in the Pacific - Kicking Goals. Communique, July 2013. Australasian Fire and Emergency Service Authorities Council (AFAC). Retrieved 26 ${ }^{\text {th }}$ of February 2015 from http://www.afac.com.au/docs/poster/pifsa.pdf?sfvrsn=4.

Punch, K. (2005). Introduction to social research: quantitative and qualitative approaches (2nd ed.). London: SAGE Publications. 
Rivera, C. (2014). Integrating climate change adaptation into disaster risk reduction in urban contexts: perceptions and practice. PLOS Current Disasters, 1, January 15th.

Schipper, E. L. F. (2009). Meeting at the crossroads?: Exploring the linkages between climate change adaptation and disaster risk reduction. Climate and Development, 1, 16-30.

Southgate, R., Roth, C., Schneider J, Shi P, Onishi T, Wenger D, Amman W, Ogallo L, Beddington J \& Murray, V. (2013). Using Science for Disaster Risk Reduction. Report of the UNISDR Scientific and Technical Advisory Group - 2013, United Nations Office for Disster Risk Reduction Retrieved 11October, 2012 from www.preventionweb.net/go/scitech.,

SPC, UNISDR \& SPREP (2013). Roadmap towards an Integrated Regional Strategy for Disaster Risk Management and Climate Change in the Pacific by 2015. Secretariat of the Pacific Community, The United Nations Office for Disaster Risk Reduction, and the Secretariat of the Pacific Regional Environment Programme. Retrieved Available at www.sprep.org/.../pdfs/.../WP_8_2_1_Att_1_PIFACC\%20Roadmap.pdf.

Thomalla, F., Downing, T., Spanger-Siegfried, E., Han, G. \& Rockstrom, J. (2006). Reducing hazard vulnerability: towards a common approach between disaster risk reduction and climate adaptation. Disasters, 30(1): 39-48.

UNDP (2009). A climate risk management approach to disaster reduction and adaptation to climate change, pp. 229-248. In: Schipper, E. L. F. \& Burton, I. (eds.) The Earthscan reader on adaptation to climate change. London; Sterling, VA: Earthscan.

UNISDR and UNDP (2012). Disaster Risk Reduction \& Climate Change Adaptation in the Pacific: An Institutional and Policy Analysis. Suva, Fiji: UNISDR, UNDP, 76 pp. Retrieved 10 October, 2012 from http://www.unisdr.org/files/26725_26725drrandccainthepacificaninstitu.pdf.

UNISDR Asia and Pacific Secretariat (2011). At the Crossroads: Climate Change Adaptation and Disaster Risk Reduction in Asia and the Pacific. A Review of the Region's Institutional and Policy Landscape. Retrieved 9 October, 2012 from

http://www.spc.int/lrd/index.php?option=com_docman\&task=doc_download\&gid=1542\&Ite mid $=10$.

UNISDR (2013a). Global Assessment Report for Disaster Risk Reduction: From Shared Risk to Shared Value: The Business Case for Disaster Risk Reduction. United Nations. Retrieved 11 October, 2013 from http://www.preventionweb.net/english/hyogo/gar/2013/en/garpdf/GAR2013_EN.pdf,.

UNISDR (2013b). The Pacific Experience in Developing Policy and Legislation on Disaster Risk Reduction and Climate Change Adaptation. The United Nations Office for Disaster Risk Reduction.

U.S Wildfire Lessons Learned Centre. (2011). After Action Reviews. Retrieved 8 May, 2012 from http://wildfirelessons.net/AAR.aspx.

Walshe, R.A., \& Nunn, P.D. (2012). Integration of indigenous knowledge and disaster risk reduction: A case study from Baie Martelli, Pentecost Island, Vanuatu. International Journal of Disaster Risk Science, 3(4), 185-194. 
Table 1: Examples of main formal agreements for the integration of DRR and CCA.

\begin{tabular}{|l|l|}
\hline Global & $\begin{array}{l}\text { United Framework Convention on Climate Change: Bali Action Plan (2007) } \\
\text { and Cancun Adaptation Framework; Joint National Action Plans (JNAP) } \\
\text { and National Adaptation Plans of Action (NAPA) }\end{array}$ \\
\hline & Hyogo Framework for Action (HFA) \\
\hline Regional & $\begin{array}{l}\text { Pacific Disaster Risk Reduction and Disaster Management Framework for } \\
\text { Action 2005-2015 }\end{array}$ \\
\hline & Pacific Islands Framework for Action on Climate Change 2006-2015 \\
\hline & $\begin{array}{l}\text { Draft Strategy for Climate and Disaster Resilient Development in the Pacific } \\
\text { (SRDP) }\end{array}$ \\
\hline National & National level policies and frameworks in addition to JNAPs, NAPAs \\
\hline
\end{tabular}


Table 2. Main rationale, barriers and enablers to the integration of DRR and CCA in the Pacific (Table based on Gero et al., 2010, 2011; Handmer and Dovers, 2013; Thomalla, Downing, SpangerSiegfried, Han \& Rockstrom, 2006; UNISDR \& UNDP, 2012; UNISDR Asia and Pacific Secretariat 2011)).

\begin{tabular}{|c|c|}
\hline \multicolumn{2}{|c|}{ SUMMARY OF ISSUES IN INTEGRATING CCA\&DRR IN THE PACIFIC } \\
\hline Rationale for Integration & $\begin{array}{ll}\checkmark & \text { Easing the burden of programming development assistance } \\
\checkmark & \text { Minimising duplication of effort and redundancies } \\
\checkmark & \text { Reducing policy development conflicts } \\
\checkmark & \text { Using resources efficiently } \\
\checkmark & \text { Securing effective outcomes especially on community level } \\
\checkmark & \text { Addressing both extreme events and long-term changes }\end{array}$ \\
\hline Barriers to Integration & $\begin{array}{ll}\checkmark & \text { Capacity constraints (inefficient coordination, lack of } \\
\text { communication, lack of political will, insufficient funds, lack of } \\
\text { capacity and expertise) } \\
\checkmark & \text { Separation of major frameworks directing CCA\&DRR (global, } \\
\text { regional, national) and funding streams } \\
\checkmark & \text { CCA\&DRR not recognised as major priorities } \\
\checkmark & \text { Lack of monitoring and evaluation tools to tease out benefits } \\
\checkmark & \text { arising from CCA\&DRR } \\
\checkmark & \text { Often focus on large-scale disasters, not prior long-term policy } \\
\checkmark & \text { work } \\
\checkmark & \text { Different disciplinary and expert communities involved } \\
\checkmark & \text { Lack of understanding climate change adaptation as a concept }\end{array}$ \\
\hline Enablers for Integration & $\begin{array}{ll}\checkmark & \text { Improved access to information (weather, climate) } \\
\checkmark & \text { Enabling environment and clear communication among actors } \\
\text { and to the public } \\
\checkmark & \text { Use of bottom-up approaches (eg local monitoring frameworks } \\
& \text { for vulnerability and resilience tracking) } \\
\checkmark & \text { Information to support decision-making (both scientific and } \\
& \text { economic; database on integration efforts) } \\
\checkmark & \text { Synergies between sectors, policies, plans and actors (coherence, } \\
& \text { cohesion and coordination; linking NGO efforts to national } \\
\checkmark & \text { priorities; harmonization of donor activities) } \\
\checkmark & \text { Development of M\&E tools to measure integration progress } \\
\checkmark & \text { Equal participatory processes; multi-stakeholder approach } \\
\checkmark & \text { Increasing resilience, using combined risk management } \\
\checkmark & \text { Combining DReches, focus on "no-regret” actions, and mainstreaming } \\
\checkmark & \text { Improved access to finance } \\
\checkmark & \text { Finding relevant entry points (eg impact assessment, } \\
\text { development initiatives including food and water security) }\end{array}$ \\
\hline
\end{tabular}


Table 3. Identified constraints that seem to hinder integration in the region.

\begin{tabular}{|c|c|}
\hline \multicolumn{2}{|c|}{ CONSTRAINTS IN IMPLEMENTING INTEGRATION IN THE REGION } \\
\hline $\begin{array}{l}\text { Uncertainty regarding the } \\
\text { changing nature of events }\end{array}$ & $\begin{array}{l}\checkmark \text { The nature of the events is already changing, simultaneous } \\
\text { multiple events with shorter or no breaks between these. This } \\
\text { impacts on the response capacity of service providers } \\
\checkmark \quad \text { Unclear how and where new risks emerge and how to manage } \\
\text { these } \\
\checkmark \quad \text { Increased exposure and vulnerability: more people and } \\
\text { infrastructure at risk }\end{array}$ \\
\hline $\begin{array}{l}\text { Current institutional } \\
\text { arrangements }\end{array}$ & $\begin{array}{ll}\checkmark & \text { Professionalization of EM services: seen as an issue for service } \\
\text { providers, not a whole of society response } \\
\checkmark & \text { Integration often seen as a specific issue for one department or } \\
& \text { unit } \\
\checkmark & \text { Most EM\&DRR under Police and not as separate entities } \\
\checkmark & \text { Decreasing agency budgets and decrease in staffing vs. } \\
\text { increasing reliance on volunteers in EM } \rightarrow \text { agency fatigue from } \\
\text { multiple on-going disasters } \\
\checkmark \\
\text { Lack of practical interaction between policymaking and } \\
\text { implementing agencies }\end{array}$ \\
\hline $\begin{array}{l}\text { Complex language and } \\
\text { complex external structures } \\
\text { and funding mechanisms }\end{array}$ & $\begin{array}{l}\checkmark \text { Different UN agencies and donors, each with their own } \\
\text { preferred language and methods } \rightarrow \text { lack of consistency; confusing } \\
\text { how to translate these to common language and at community level }\end{array}$ \\
\hline Limited M\&E mechanisms & $\begin{array}{l}\checkmark \text { Currently weak M\&E mechanisms to reliably measure the extent } \\
\text { of change on the ground }\end{array}$ \\
\hline Logistical challenges & $\begin{array}{ll}\checkmark & \text { Geographical dispersal of populations a logistical challenge: } \\
& \text { SIDS } \rightarrow \text { many small islands, Australia: many remote } \\
\text { communities } & \\
\checkmark & \text { How do you move people out of harms way quickly? }\end{array}$ \\
\hline
\end{tabular}


Table 4. Identified strategies to enable better integration in the region.

\begin{tabular}{|c|c|}
\hline \multicolumn{2}{|c|}{ ENABLERS FOR IMPLEMENTING INTEGRATION IN THE REGION } \\
\hline Increased Response Capacity & $\begin{array}{l}\checkmark \text { Capability assessments (Australian National Capability Picture) } \\
\text { to understand the expertise and capacity across country, } \\
\text { including equipment and personnel } \\
\checkmark \text { Liaison officers placed in each state before any major events } \\
\checkmark \text { Investing in on the ground capacity eg community level training: } \\
\text { Help communities to have the skills and capabilities to respond } \\
\text { to disasters } \\
\checkmark \text { Clear policy arrangements for EM\&DRR personnel movement } \\
\text { in the region during emergencies: } \\
\text { - Australian White paper on country entry requirements and } \\
\text { standards for receiving EM personnel to Australia (policy } \\
\text { framework) }\end{array}$ \\
\hline Strengthening Partnerships & 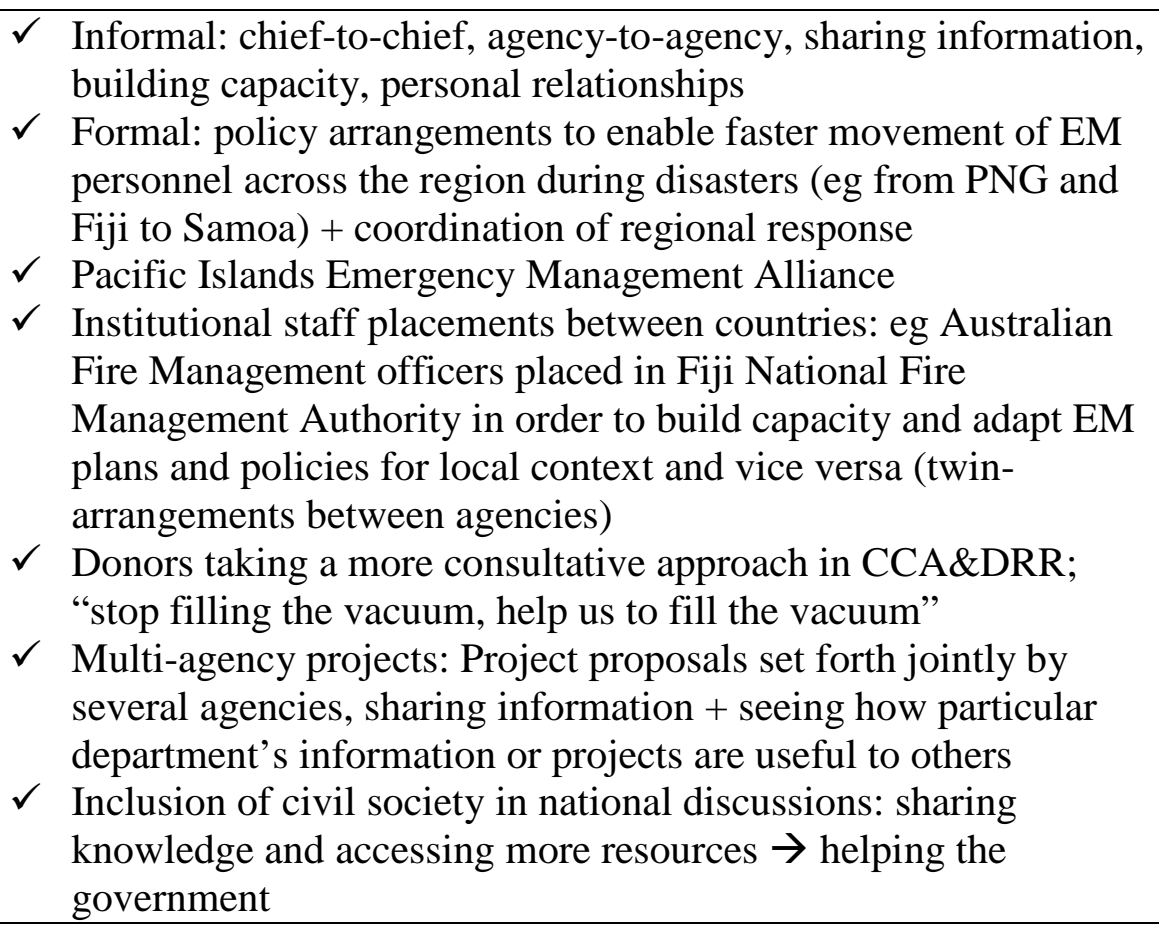 \\
\hline $\begin{array}{l}\text { Consistency in methods and } \\
\text { priorities }\end{array}$ & $\begin{array}{l}\checkmark \text { Donors and external agencies need to follow countries' own } \\
\text { frameworks and legislations and preferred tools rather than each } \\
\text { bringing their own }\end{array}$ \\
\hline Leadership & $\begin{array}{ll}\checkmark & \text { Political will to integrate these issues and take responsibility } \\
\checkmark & \text { Focal points for national coordination: } \\
\checkmark & \text { Opportunity to provide consistent key messages and pursue a } \\
& \text { common approach }\end{array}$ \\
\hline $\begin{array}{l}\text { Linking science to policy and } \\
\text { access to data }\end{array}$ & $\begin{array}{ll}\checkmark & \text { Linking scientific research and knowledge to policy and } \\
\text { decision-making processes } \\
\checkmark & \text { Having data available }\end{array}$ \\
\hline $\begin{array}{l}\text { Legislation enables } \\
\text { integration }\end{array}$ & $\begin{array}{l}\checkmark \text { Once eg building codes are legislated, one can demand } \\
\text { accountability and responsibility; legislation can also drive } \\
\text { integration }\end{array}$ \\
\hline
\end{tabular}

